\title{
Indelével como a flor: A teofania da Virgem Maria aos olhos e ouvidos de Cartola
}

\author{
Antonio Passos de Souza* \\ Carlos Eduardo Brandão Calvani** \\ Glaucio José Couri Machado***
}

\section{RESUMO}

No rastro do interesse despertado no âmbito das Ciências da Religião no Brasil pela presença de abordagens que se aproximam de temas religiosos em canções não religiosas, o presente artigo visa a focalização de uma nuance em meio a esse cancioneiro: canções criadas e divulgadas em contextos artísticos e comerciais sem vínculos com instituições religiosas, porém, com uma profundidade teológica e caracterização que as coloca como que aspirantes à condição de música religiosa de uma determinada confissão. $\mathrm{O}$ artigo baseia-se em estudos recentes sobre aspectos religiosos da MPB, escritos a partir de elementos da teologia da cultura de Paul Tillich. O texto apresenta algumas canções ligadas a devoções marginais do catolicismo popular, bem como a devoções marianas, concentrando-se posteriormente em uma análise específica do samba "Dê-me Graças, Senhora", uma composição incorporada ao repertório do sambista Cartola, lançada originalmente no álbum "Cartola 70 Anos" (1979). A análise demonstra que a aproximação entre canções não religiosas e temas religiosos pode se dar de modo explícito com a citação expressa de símbolos religiosos ou de forma mais sutil, implícita, por meio de uma inserção discursiva da canção em reflexões basilares para a teologia e a religião. Palavras-chave: Cartola; religião; samba; canção; MPB.

* Graduado em História (UFS, 1992) e discente-especial do PPGCR/UFS. E-mail: mensagem.passos@gmail.com

** Teólogo, Mestre e Doutor em Ciências da Religião (1994 - UMESP). Professor do PPGCR (UFS).E-mail: cecalvani@hotmail.com.

*** Cientista Social (1993 - UFJF), Mestre em Ciência da Religião (1998 - UFJF); Doutor em Inform\&aac ute;tica na Educação (2007 - UFRGS) Professor Associado II da Universidade Federal de Sergipe (UFS); Professor do Programa de Pós-graduação em Ciências da Religião (UFS). 


\title{
INDELIBLE AS A FLOWER: VIRGIN MARY THEOPHANY ACCORDING TO CARTOLA'S EYES AND EARS
}

\begin{abstract}
Following aroused interests to Religious Sciences scope in Brazil by the presence of ideas near religious themes in non-religious songs, this paper focus on a nuance in the midst of this song selection: songs created and disseminated in artistic and commercial contexts non-linked to religious institutions, but with a theological depth and characterization that places them as if aspiring to the condition of religious music of a certain confession. The article is based on recent studies concerning religious aspects of $\mathrm{MPB}$, that have been written considering elements of Paul Tillich's Theology of Culture. The text presents some songs linked to marginal devotions of popular Catholicism, as well as Marian devotions, subsequently concentrating on a specific analysis of the samba "Dê-me Graças, Senhora", a composition incorporated into the repertoire of the samba singer Cartola, originally released on the album "Cartola 70 Anos" (1979). The analysis demonstrates the approximation between non-religious songs and religious themes can happen explicitly with the express mention of religious symbols or in a more subtle, implicit way, through a discursive insertion of the song in basic reflections for theology and religion.
\end{abstract}

Key words: Cartola; Religion; Samba; Songs; MPB.

\section{Introdução}

A canção, simplificadamente entendida como a composição conjunta e unificada de um texto escrito (letra) associado a uma melodia musical (música) teve suas possibilidades de preservação e divulgação imensamente ampliadas a partir da consolidação industrial da fonografia. Desse modo, o enorme acervo de canções brasileiras gravadas desde o início do século XX, incluindo as que são divulgadas a cada dia no tempo presente, hoje pode ser acessado por diversos meios: o disco de vinil, fitas magnéticas, CDs e DVDs, meios de comunicação de massa e pela internet.

$\mathrm{O}$ acervo de criações musicais brasileiras classificadas como canções deixa evidente não apenas uma grande variedade de ritmos, melodias, harmonias, arranjos e interpretações vocais, como também de temas abor- 
dados nas letras, ligados não somente aos dramas dos relacionamentos interpessoais (ciúmes, paixões), políticos ou sociais, mas também a temáticas associáveis à filosofia ou a questões de inspiração religiosa.

Para sugerir a amplitude dos temas alcançados por esse acervo de canções, pode-se perguntar: que assunto teria escapado ao repertório de compositores e intérpretes que vão, por exemplo, desde Padre Zezinho até Rogério Skylab; das Mercenárias a Tiê; de Arrigo Barnabé a Nadir da Mussuca; da Banda de Pau e Corda aos Titãs; de Geraldo Vandré a Karol Conká; de Lady Zu a Zé Ramalho; de Clemilda a Gabriel - o pensador; etc? Esse imenso mosaico que reúne estilos e figuras aparentemente muito distanciadas artisticamente, tanto em relação aos temas que abordaram ou abordam quanto ao modo de abordagem (forma e estilo), evidencia a ampla liberdade exercida pelos compositores na escolha dos temas cantados em suas canções. No conjunto do acervo a imensa variedade temática prevalece mesmo considerando a existência de mecanismos de controle ocasionais exercidos sobre a criatividade artística, a exemplo de alguma interferência vinculada a interesses comerciais, por vezes atribuída às empresas fonográficas e exercida sobre seus artistas contratados (DIAS, 2000).

Em meio a essa liberdade criativa que parece caracterizar o acervo aqui identificado como a canção brasileira com registro fonográfico (agora também digital), para além da função relacionada ao entretenimento mais instantâneo, podemos observar instigantes diálogos temáticos entre as canções e outras áreas da cultura, tais como os temas filosóficos e religiosos. Despertando para esses diálogos, a Ciência da Religião praticada no Brasil começa a manifestar interesse acerca de relações que podem ser buscadas entre o fenômeno religioso e canções de um repertório não identificado como religioso. Dois artigos publicados neste início do século XXI e aqui trazidos a título de exemplos, entre outros, tratam da presença explícita ou implícita de temáticas religiosas em canções criadas e veiculadas originalmente em contextos artísticos e comerciais desvinculados de práticas ou instituições religiosas: "Que samba é esse, malandro? Uma análise teológico-existencial de sambas de Cartola a partir da teologia da cultura de Paul Tillich" (TADA, 2010) 
e "Coragem de Ser frente à angústia do destino e da morte na canção Cajuína, de Caetano Veloso" (CALVANI, 2016)․․

\section{Canções populares com temas religiosos}

Os autores desses dois artigos elaboraram suas análises a partir da teologia da cultura de Paul Tillich. Tada se debruça sobre cinco sambas gravados pelo compositor e intérprete musical Cartola - "Preciso me encontrar" (Candeia), "Quem me vê sorrindo" (Cartola e Carlos Cachaça), "Alvorada" (Cartola, Carlos Cachaça e Hermínio Bello de Carvalho), "O mundo é um moinho" (Cartola) e "Grande Deus" (Cartola) - propondo-se a fazer uma análise "teológico-existencial" (TADA, 2010, p. 66) por ter percebido nessas canções a presença de temáticas comumente tratadas pela religião.

Nas letras de quatro dos cinco sambas é identificada uma "preocupação existencial em sentido profundo" (TADA, 2010, p. 66), o que atribui a essas composições musicais uma dimensão que alcança algum diálogo com os discursos religiosos, nem sempre explícitos à primeira vista (ou audição). Ou seja, a seu modo, esses sambas falam "sobre os limites da existência humana" (TADA, 2010, p. 70) e assim tocam em um tema fundante do discurso teológico e das práticas religiosas. Já no samba "Grande Deus", no qual a referência a uma simbologia religiosa está explícita desde o título, a abordagem do tema religioso é apontada como superficial ou, com as palavras de Tada, "no sentido tillichiano de religião, esse samba é religioso apenas em seu formato, ou seja, sua linguagem e seus elementos rasos, mas não há profundidade religiosa" (TADA, 2010, p. 77).

A análise de Tada, embora ancorada teoricamente em Tillich, incorre em um problema metodológico identificado por Calvani (2015, p. 42): "dar atenção apenas à poética e à letra, desprezando a musicalidade e separando agressivamente, dois elementos que, uma vez dissociados, prejudicam a interpretação ao cindir o que é uma unidade. Tal mutilação representa exatamente a decomposição de uma composição, ou seja, de uma estrutura que se torna irreconhecível sem os elementos que

1 Publicado como capítulo de livro, esse texto foi reescrito na forma de ARTIGO ACADÊMICO E PUBliCADO EM CORRELATIO COM O TÍtUlo: “EXISTIRMOS... A QUE será que se destina? Choque ontológico, angústia e coragem de ser na canção Cajuína” (CALVANI, 2017). 
a fazem ser o que é". Nesse caso, considerou-se apenas a letra, sem muita atenção à música que a acompanha, o que pode induzir leitores que não conhecem a canção a reforçar preconceitos de que um estilo como o samba não seria digno de aludir com profundidade a certos temas religiosos.

$\mathrm{Na}$ busca por superar esse problema que diz respeito ao método de análise, Calvani evoca o conceito de "espiritualidades não-religiosas" para referir-se a "manifestações culturais que se afastam de referenciais ligados a sistemas religiosos (cultos, orações, liturgias, rituais específicos ou o tema da mística), mas que lidam com temas semelhantes" (CALVANI, 2016, p. 179) e essa conceituação claramente recepciona as aproximações entre a canção e a religião descritas por Tada para os cinco sambas por ele analisados, gravados por Cartola. Desse modo, estilos musicais tradicionalmente identificados como não-religiosos (o samba, p.ex, ou o rap), podem tornar-se meios valiosos para se promover um diálogo profícuo entre religião e cultura, sem a necessidade de menção explícita ao fenômeno religioso, mas, por meio de uma inserção discursiva da canção em reflexões basilares para a teologia e a religião.

Esse tema é aprofundado na análise da canção "Cajuína" (Caetano Veloso), a partir do pressuposto tillichiano de que a filosofia, a religião e a arte são diferentes "modos através dos quais o ser humano se relaciona com a realidade, atribuindo-lhe sentido" (CALVANI, 2016, p. 180). Posto isso cabe inferir que seja próprio desses três campos da cultura, embora por caminhos diferenciados, manifestarem-se sobre conteúdos semelhantes. Passando ao trato com "Cajuína", Calvani rompe a barreira de uma análise conteudista, apenas da letra, e empreende uma reflexão formal mais ampla, atenta à unidade da canção, considerando não apenas o texto escrito, mas, sua musicalidade na forma de "canção". Contudo, a justificativa da escolha de "Cajuína" para ser analisada do ponto de vista da aproximação entre a canção não explicitamente religiosa e a religião, dá-se por motivo semelhante ao que levou Tada a analisar as canções do repertório de Cartola. Ou seja, a presença na canção de temas centrais para a religião, no caso de "Cajuína", com as palavras de Calvani, a "angústia do destino, da morte e da vacuidade de sentido" (CALVANI, 2016, p. 180). 
A argumentação seguida por Calvani fundamenta-se em sua própria pesquisa de doutorado (1998), que analisa o desenvolvimento da teologia da cultura de Tillich entre 1919 e 1925, argumentando que "a tarefa da teologia da cultura é refletir sobre a substância ou o conteúdo (Gehalt) presente nas várias esferas culturais revelando seu sentido, significado e profundidade espiritual" (CALVANI, 1998, p. 47). Calvani esclarece:

Gehalt é o conteúdo substancial, mais profundo que o conteúdo objetivo (Inhalt). Inhalt é a realidade objetiva em sua existência factual, enquanto Gehalt tem a ver com o sentido, a substância espiritual que dá sentido essencial a toda forma. Dessa forma, o Inhalt é acidental, e por isso, não é o nível que lhe interessa. Já o Gehalt (conteúdo substancial) é essencial, enquanto a forma (Form) é o elemento mediador do Gehalt para o Inhalt (CALVANI, 1998, p. 49).

Aplicando-se tais categorias a "Cajuína" (Caetano Veloso) ou a "Grande Deus" (Cartola), pode-se dizer que ambas são "Form", pois toda canção é uma forma, um elemento mediador. Quanto ao Inhalt (conteúdo acidental) - no caso de Cajuína, temos um xote que tematiza um enigma em torno da palavra "Cajuína" enquanto no caso de Cartola uma oração de súplica em forma de samba. Ambas, tanto um xote como um samba podem ser portadores de Gehalt (conteúdo substancial), que diz respeito às preocupações humanas mais profundas.

\section{Devoções marginais na MPB}

Toda a discussão até aqui alimentada pretendeu demonstrar que fora do âmbito e de uma área de influência direta das instituições religiosas e das suas práticas a canção brasileira como modo específico de expressão artística e não religiosa canta e reflete temas religiosos e filosóficos de modos variados. A proposição central deste artigo é ouvir e olhar de modo específico para uma nuance da canção criada fora do ambiente institucional religioso, porém, portadora de alguma proximidade com o tema religião. $O$ foco será a canção criada e divulgada originalmente em um contexto artístico e comercial, sem vínculos com instituições religiosas, porém, com uma caracterização que as coloca 
como que aspirantes à condição de música religiosa de uma determinada confissão, por expressarem uma devoção explícita.

Apurando os ouvidos na direção das canções associadas ou associáveis ao catolicismo, percebemos que se há um filão inter-religioso cristão classificado hoje no Brasil como música gospel (SOUZA, 2005) e que produz canções bem recebidas por setores da Igreja Católica no Brasil, há também canções que parecem expressar uma vocação nata para virem a ser recepcionadas como religiosas, embora tenham sido originalmente criadas e veiculadas em contextos dissociados de influência eclesiástica direta. São canções criadas fora dos círculos de produção musical apadrinhados pela Igreja Católica, por artistas cujo conjunto das respectivas obras musicais não é identificado como "religioso", porém, portadoras de uma explícita intenção de louvação a símbolos católicos. Para utilizar uma nomenclatura comum nos vários documentos papais sobre música, publicados no decorrer do século XX e início do XXI, seria algo como um louvor musical de origem "profana" oferecido ao "sagrado" e assim portador de uma atitude artística de independência diante de controles institucionais religiosos exercidos sobre a produção da música religiosa. Todavia, mesmo com essa desvinculação no ato de criação e divulgação inicial, algumas dessas canções acabam por conquistar os corações da comunidade católica e chegam a ser cantadas em celebrações. Por analogia às muitas devoções não oficiais que integram o catolicismo no Brasil (PEREIRA, 2011), essas canções, pode-se dizer, manifestam um caráter originário devocional marginal em relação aos repertórios religioso e litúrgico oficiais.

O tema das devoções católicas não oficiais é o assunto do livro "Interfaces do Sagrado - Catolicismo Popular: O imaginário religioso nas devoções marginais" (PEREIRA, 2011). As devoções católicas não oficiais, que abundam no Brasil, são crenças e ritos iniciados, alimentados, praticados e mantidos por fiéis católicos à margem da orientação centralizada da Igreja. Uma espécie de fé, se não concorrente, ao menos paralela à fé nos santos e santas canonizados por Roma. Para o fiel devoto, a fé no Padim Ciço, em Antoninho da Rocha Marmo, no Menino da Tábua, em Frei Damião, no Negrinho do Pastoreio, em Santa Izildinha, entre tantas outras, não parece abalada pela exclusão em relação à chancela da oficialidade católica. De modo análogo, há 
também uma presença expressiva de canções devocionais no acervo fonográfico brasileiro, criadas e interpretadas independentemente de solicitação, colaboração ou concordância prévia da Igreja. Canções que, ao serem publicamente divulgadas, podem até vir a ser recepcionadas por indivíduos ou por grupos como veículos de manifestação da fé que os agrade e os eleve tanto quanto ou mais do que as canções do repertório católico litúrgico e gospel (este, aqui identificado como o repertório composto e divulgado por artistas cujas carreiras estão inteiramente ou principalmente voltadas para a produção de uma música exclusivamente religiosa).

Desse conjunto de canções que estamos nominando como devocionais, muitas se referem à simbologia oficial da Igreja, mas, há também aquelas que prestam louvores aos cultos devocionais marginais. No livro já mencionado sobre catolicismo popular (PEREIRA, 2011), constam o registro de três canções com esse duplo traço marginal de devoção - além de terem emergido sem vínculo direto com a produção musical associada à Igreja Católica, referem-se à devoções marginais: "Negrinho do Pastoreio", uma composição de Barbosa Lessa (PEREIRA, 2011, p. 52) e mais duas dedicadas à devoção ao Menino da Tábua, ambas gravadas pela dupla Pardinho \& Pardal: "O Menino da Tábua" (PEREIRA, 2011, p. 109-110) e "Os Milagres do Menino da Tábua" (PEREIRA, 2011, p. 111-112).

\section{Devoções marianas na MPB}

No repertório mais amplo, formado por canções aqui chamadas de devocionais apenas por terem sido originalmente criadas e veiculadas em contextos artísticos independentes da influência direta de instituições religiosas, mas que se referem à simbologia católica oficial, uma divindade bastante cantada tem sido a Virgem Maria. Algumas canções a ela dedicadas tornaram-se grandes sucessos de público, a exemplo de "Ave Maria no Morro" (Herivelto Martins, 1942), "Romaria" (Renato Teixeira, 1977) e "Nossa Senhora" (Roberto Carlos e Erasmo Carlos, 1993). Mais uma canção, essa incorporada aos repertórios de três dos mais aclamados nomes da música brasileira, com carreiras artísticas iniciadas no decorrer do século XX, para alargar a exemplificação da variedade de inserção desse tema devocional no universo da canção 
brasileira, é "Baião da Penha" (Guio de Moraes e David Nasser), gravada por Luiz Gonzaga no disco de 78 rotações "Sabiá/Baião da Penha" (1951), por Caetano Veloso no álbum "Circuladô" (1991) e por Gilberto Gil nos álbuns "As canções de Eu, Tu, Eles" (2000) e "São João Vivo" (2001). Porém, o foco específico deste artigo advém da análise de uma canção também dedicada ao culto à Virgem Maria, mas, seguramente, não tão difundida quanto às citadas anteriormente. Trata-se de "Dê-me Graças, Senhora" (Cartola e Cláudio Jorge), lançada originalmente no álbum "Cartola 70 Anos" (1979).

Em “Ave Maria no Morro" (Herivelto Martins) é feita uma síntese cênica de uma zona urbana, o morro, ocupado por habitações rudimentares. Prevalece, entretanto, uma exaltação de dádivas naturais que parecem se sobrepor às limitações de ordem material: a "alvorada", a "passarada", o "alvorecer", a "sinfonia de pardais" e uma real ou metafórica proximidade com o céu. Coroando cotidianamente o sentimento de gratidão pelas dádivas "o morro inteiro, ao fim do dia, reza uma prece, Ave Maria”. Além do que consta expresso na letra de modo explícito, o clima musical melancólico e as sensações transmitidas de conforto espiritual e de desapego mundano são indícios estimulantes para um aprofundamento da busca de outras camadas de diálogo entre essa canção e as temáticas religiosas. A receptividade dessa canção é tamanha que ultrapassa inclusive fronteiras, tendo sido gravada até mesmo pela banda alemã de rock "Scorpions" em 2012².

"Baião da Penha" (Guio de Moraes e David Nasser), "Romaria" (Renato Teixeira) e "Nossa Senhora" (Roberto Carlos e Erasmo Carlos), guardando nuances particulares cada uma delas, são canções de súplica. Nessas três composições musicais, em ambientações diversas e de modos diferenciados, pedidos são dirigidos por um indivíduo a Maria Santíssima. Em "Baião da Penha" o pedinte expõe sua necessidade de fazer demonstração sacrificial da fé ao "subir a Penha a pé", para só então orar. Ainda assim, conserva dúvidas quanto ao alcance do seu gesto: "minha voz talvez não tenha, o poder de te exaltar". Ao pedir, mostra-se solidário mesclando súplicas pessoais e coletivas: pede proteção para seu baião (ritmo da canção), para o lar e ainda para a

Link para audição - https://www.youtube.com/watch?v=b9-7qjfETXs (Acesso em 20.07.2021). 
"gente brasileira" para que tenha "paz pra trabalhar" - semelhante solidariedade também será encontrada nas súplicas cantadas em "Dê-me Graças, Senhora", de Cartola.

$\mathrm{Na}$ canção "Romaria" a busca do apoio celestial e o pedido se apresentam após uma longa e extenuante caminhada, uma vida inteira de desventuras. O pedinte é identificado como um caipira, um homem cuja vida, "cumprida a sol", foi quase inteiramente tomada pela lida rural ou pela exploração exaustiva da sua força de trabalho e por ilusões mundanas. Ao passo em que as esperanças do personagem cantante e cantado restaram trituradas, transformadas em poeira. Essa é uma caracterização extensiva ao ambiente, no qual as individualidades pouco parecem se distinguir. O pai também "foi peão", a mãe "solidão" e os irmãos "perderam-se na vida em busca de aventuras". Em meio a todo esse turbilhão existencial e mesmo sem sequer ter aprendido a rezar, o humano peão angustia-se com o aprofundamento da percepção do destino que lhe coube e por um ouvir dizer, entrega-se à força da multidão e em romaria chega à presença da imagem de Nossa Senhora Aparecida. Como não sabe rezar, busca a cumplicidade de Maria Santíssima entregando-lhe o olhar e tal como na canção de Cartola e Cláudio Jorge, embora com uma carga dramática bem diferenciada, o olhar terá papel decisivo na interação entre o humano e o divino.

Distanciando-se de "Ave Maria no Morro", "Baião da Penha" e "Romaria", as canções "Nossa Senhora" e "Dê-me Graças, Senhora" quase não trazem em suas letras qualquer informação sobre o que poderíamos chamar o entorno social da relação entre o humano e o divino, nessas, há um fechamento do foco no momento do encontro em si. "Nossa Senhora" é toda ela uma súplica à Virgem Maria: por proteção, por cura, por pureza de sentimentos, por perdão, por fé e calmaria, culminando no refrão com a expressão de uma entrega da vida e do destino do pedinte nas mãos da divindade. Somente em um trecho é feita uma alusão a alguma externalidade, quando o indivíduo comenta que não está sozinho no ato da súplica, pois, "grande é a procissão a pedir", e estende o seu pedido para o coletivo dos suplicantes: "Rogai por todos nós vossos filhos meus irmãos".

É relevante registrar uma diferenciação marcante entre "Dême Graças, Senhora" e as demais. Todas as outras canções, em suas 
narrativas, descrevem situações inscritas em uma dimensão real física, natural. Os atos de fé e oração mencionados projetam-se para um alémmundo, mas, são vivenciados exclusivamente por seres humanos, de carne e osso. Já "Dê-me Graças, Senhora" penetra o terreno do sobrenatural ao descrever e dramatizar uma aparição espiritual da Virgem Maria diante de um indivíduo, seguida por um breve diálogo.

Visão e descrição de uma aparição divina: a teofania da Virgem Maria a Cartola

A canção "Dê-me Graças, Senhora", vale relembrar, não consta no artigo "Que samba é esse, malandro? Uma análise teológico-existencial de sambas de Cartola a partir da teologia da cultura de Paul Tillich" (TADA, 2010). Para iniciar aqui o contato com o samba "Dê-me Graças, Senhora", sugerimos que seja previamente ouvido 3 para em seguida enveredarmos por uma leitura da letra:

O Sol, a Lua, a Terra, o Mar

É um mundo novo em teu olhar

Estrelas vejo a cintilar

Que brisa amena ao te fitar

És indelével como a flor

Qual foi o Deus, teu escultor?

E ouvia a voz e a voz dizia

- Eu sou a mãe de Deus, Virgem Maria

Dê-me graças Senhora

Um sorriso a quem chora

Onde há ódio eu vos peço

Que ponha o amor e assim

$\mathrm{Eu}$ serei mais feliz que sou

Cartola é o tipo de artista cujo conjunto da obra musical carrega uma marca muito pessoal do estilo do compositor, mesmo quando criando em parceria, sem a evidência de grandes variações ou aber-

Link para audição de "Dê-me Graças, Senhora" - https://www.youtube.com/watch?v=7vW006dwVkU (Acesso em 21.04.2021). 
turas para a influência de musicalidades diversas. Qualquer um dos sambas de Cartola - considerados o ritmo, a melodia, a harmonia e o vocabulário utilizado nas letras - é, sobretudo e de modo típico, um samba de Cartola. "Dê-me Graças, Senhora" é um desses sambas. Tratase de uma composição com andamento intermediário, aproximandose dos chamados samba-canção - sambas mais lentos, com melodias mais elaboradas e geralmente associados a uma atmosfera romântica. O próprio Cartola deixou gravada em uma entrevista a sua preferência pelo andamento samba-canção (MOURA, 1998).

A letra e a melodia de "Dê-me Graças, Senhora", estão estruturadas em três momentos: uma primeira parte (cantada pelo eu lírico em primeira pessoa); o refrão (cantado por uma segunda personagem que responde ao eu lírico); e a segunda parte (uma súplica, novamente cantada pelo eu lírico).

Do início até meados da letra (toda a primeira parte) é sugerido um encontro, uma troca de olhares, talvez um flerte seguido de um diálogo entre o eu lírico que se manifesta em primeira pessoa e outro alguém cuja identidade só será revelada no refrão. Durante o olhar inicial o primeiro personagem em ordem de aparição começa a pronunciar frases como que pensamentos em voz alta, mesclados com fragmentos de visões e sensações. Toda a primeira frase da primeira parte da letra apenas cita monumentais elementos da natureza - "O Sol, a Lua, a Terra, o Mar" - para logo em seguida, na segunda frase, ficar claro que a visão ou a lembrança daqueles elementos da natureza, amiúde presentes em narrativas cosmogônicas e em simbologias religiosas, está relacionada ou foi induzida pela troca de olhares - "É um mundo novo em teu olhar".

O jogo entre os olhares, os elementos cósmicos e as sensações, continua nas duas frases seguintes - "Estrelas vejo a cintilar / Que brisa amena ao te fitar". Após o primeiro, enigmático e sugestivo contato descrito como um olhar nos olhos, o personagem que fala na primeira parte da letra faz um comentário sobre a imagem que vê à sua frente e essa frase instaura-se como o momento mais profundo de um diálogo, encontrado no canto, sobre uma temática que alcança a filosofia e, implicitamente, a religião: 


\section{"És indelével como a flor"}

Sobre o que está sendo visto pelo primeiro personagem da canção e ainda não é dado ao público conhecer, é dito que não se pode apagar ou fazer desaparecer - que é indelével, permanente, perene. Curiosa - e aí está um belíssimo momento poético extraído da canção brasileira - é a atribuição da perenidade, comparativamente, também a um ente com evidente fragilidade natural em escala humana: a flor. Após mencionar o sol, a lua, a terra, o mar e as estrelas, os compositores colocam como exemplo de permanência a frágil flor, que pode ser facilmente destruída pela ação direta e imediata de uma única mão humana. Logo, percebe-se, os autores não podem estar referindo-se à flor individualizada no mundo natural, material. Sugerindo um possível diálogo com a filosofia, a indelével flor soa como reminiscência do idealismo nos termos formulados por Platão. Em sua canção, poeticamente, Cartola e Cláudio Jorge parecem mesmo descrever a ideia platônica de flor, o modelo ideal de todas as flores percebidas no mundo natural. Aquela, porém, imutável e existente apenas no mundo das ideias. Na filosofia de Platão as "ideias, são arquétipos ontológicos, caracterizando-se pela transcendência, pela universalidade", além disso, "são entidades que possuem vida e movimento" (BASTOS, 1987, p. 23). Onde estaria essa flor perenal senão em uma dimensão divina, etérea, celestial? Não seria o indelével um sinônimo do eterno - aquilo que não pode sofrer a ação do tempo? E nessa sutil insinuação do celestial por meio da mencionada atemporalidade da flor anuncia-se o que virá logo a seguir: a revelação de uma presença divina na cena.

Essa urdidura de diálogos entre a arte (na forma de canção) e a religião (em muitas ocasiões com a filosofia também sentada à mesa), vale frisar, não indica a intencionalidade de incidência filosófica ou religiosa (no tocante à aproximação implícita) por parte dos compositores no processo de criação das canções. Esses diálogos vêm de outra fonte, digamos, mais estrutural, profunda e próxima à literatura chamada "mística".

A sensação após uma audição autêntica e respeitosa que vai além do entretenimento apenas instantâneo de "Dê-me Graças, Senhora" é a de que o personagem que fala na primeira parte da letra é tomado progressivamente pela força da presença de uma imagem que é vista por ele, de 
modo que é apartado de tudo mais ao seu redor, como que elevado num êxtase e, em meio ao deslumbre, lança-se em um diálogo ao perguntar:

\section{"Qual foi o Deus, teu escultor?"}

Passa então a ouvir uma voz que responde, no refrão da canção:

"Eu sou a mãe de Deus, Virgem Maria"

Apesar da resposta clara contida no refrão, nem tudo na canção é apresentado de modo explícito. Ao contrário, pairam no ar insinuações sem respostas e assim a ambientação revela-se em harmonia com a cena descrita na qual há interação entre o sensorial, o racional, o intuitivo e o transcendental. A menção a um possível escultor pode sugerir que a imagem vista da Virgem Maria seja uma escultura, como tantas que podem ser encontradas em igrejas ou nas casas de fiéis católicos; porém, há também a insinuação de que Deus poderia ter sido o escultor. Esteve, portanto, o nosso personagem diante de uma imagem materialmente esculpida que veio a expressar-se por meio da fala ou frente a frente com uma aparição espiritual da Virgem Maria que a princípio o confundiu fazendo-o pensar que fosse uma escultura? Contribuindo com o preciosismo da canção e mantendo-a envolta em um clima enigmático, nela essas questões não estão respondidas, ficando possíveis interpretações a cargo dos ouvintes.

As letras das canções, de modo geral, são textos curtos e em muitas gravações são cantadas mais de uma vez. Todavia, nesses pequenos escritos, pode-se encontrar o uso de diferentes gêneros de linguagem. Em "Dê-me Graças, Senhora" ouvimos uma mescla de fragmentos de expressão lírica e narração descritiva seguida por um diálogo entre dois personagens. Continuando o percurso pelas palavras cantadas nessa canção, sugerimos experienciar aqui o emprego de um instrumental vindo da análise do uso diversificado de linguagens escritas em textos dramatúrgicos (PALLOTTINI, 2008), pois, "Dê-me Graças, Senhora" é um samba que descreve e dramatiza uma cena, com intercalação de diferentes gêneros de linguagem.

Nas cinco primeiras frases soa um entremear, com limites tênues, entre o uso de uma voz lírica (expressando sensações) e uma descri- 
ção, desembocando na pergunta: "Qual foi o Deus, teu escultor?". As expressões "ouvia a voz" e "a voz dizia" localizam a vivência descrita como algo que aconteceu no tempo passado e que está sendo narrado posteriormente. Com isso, soa caracterizada a inserção de linguagem épica no início da letra. Entretanto, o fato que vinha sendo contado passa a ser encenado por meio das falas de dois personagens distintos que dialogam entre si, havendo assim transição para uma linguagem dramática. Essa variação de linguagens ao lado de outros elementos, por contraste, destacam o contorno entre os diferentes momentos da canção: a descrição inicial da cena entremeada a uma expressão lírica (primeira parte), o diálogo efetivo com a divindade (refrão) e a súplica final (segunda parte).

Sensível e em harmonia com o contido na composição, ao levá-la ao registro fonográfico no álbum "Cartola 70 Anos" (1979), o arranjador Nelson Martins dos Santos ${ }^{4}$ caracterizou o diálogo de modo explícito ao colocar o refrão, único trecho da letra no qual quem fala (ou melhor, canta) é a Virgem Maria, na voz de um grupo vocal feminino. $\mathrm{Na}$ introdução e durante o canto do refrão, reforçando a aproximação desse samba com o catolicismo tradicional, pode ser ouvida a presença harmônica de um instrumento de modo geral incomum no ambiente do samba, instrumento cujo timbre foi durante muito tempo o único permitido na música sacra católica, o órgão. No mais, "Dê-me Graças, Senhora" é um típico samba de Cartola.

Após o diálogo que deixou o sambista (ou um personagem criado por ele) ciente de estar diante de uma aparição espiritual de Maria Santíssima, são dirigidas a ela algumas súplicas:

Dê-me graças Senhora

Um sorriso a quem chora

Onde há ódio eu vos peço

Que ponha o amor e assim

$\mathrm{Eu}$ serei mais feliz que sou

4 No endereço https://discografia.discosdobrasil.com.br/discos/cartola-70-anos foi consultada a ficha técnica do álbum "Cartola 70 Anos" (1979), na qual encontram-se identificados o arranjador, bem como os músicos e os instrumentos musicais utilizados para a gravação de cada uma das faixas (Acesso em 03.05.2021). 
Nas súplicas cantadas na última parte do samba "Dê-me Graças, Senhora", podemos ouvir o eco de um dos mais enfatizados mandamentos cristãos: a renúncia ao interesse pessoal em solidariedade ao outro, o amor ao próximo. Diante da extraordinária aparição de Maria Santíssima, o compositor não coloca na boca do personagem da canção nenhum pedido muito particular para ele mesmo. Pede graças de modo genérico e um sorriso para quem chora. Pede que o ódio seja substituído pelo amor e declara que isso o fará mais feliz.

\section{Considerações finais}

Concluída a análise proposta para a canção "Dê-me Graças, Senhora" e olhando agora retroativamente para o artigo de Tada, coloco a seguinte questão a título de especulação: caso tivesse sido incluído no rol dos sambas do repertório de Cartola analisado naquele artigo, "Dê-me Graças, Senhora" teria sido classificada como uma canção que se refere à religião apenas superficialmente ou em sentido profundo? Em sua face mais devocional e mais imediatamente perceptível, explícita, a canção descreve uma aparição de Maria Santíssima, seguida de um curto diálogo entre a divindade e um ser humano - o que por si só já se coloca como um mistério para a razão. Porém, pela simples inserção de uma única frase - "És indelével como a flor", o samba "Dê-me Graças, Senhora" alcança um diálogo religioso profundo, pois, na referência à perpétua flor está contida uma reflexão sobre o temporal e o eterno.

Com isso, acreditamos evidenciar-se que a imensa e diversificada profusão de formas e dos conteúdos (o que é cantado e o como é cantado), característica do acervo das canções brasileiras, possibilitam uma notável variedade de diálogos, entre os quais aqueles que podem ser ouvidos e interpretados a partir de muitas dessas canções e que acenam para temáticas religiosas. São expressões artísticas que podem ser identificadas como a manifestação de espiritualidades não-religiosas (CALVANI, 2014). No caso específico do samba "Dê-me Graças, Senhora", considerando as possibilidades esboçadas na teoria tillichiana (TADA, 2010), trata-se de uma canção na qual é possível ouvir a articulação de um diálogo que pode soar superficial a uma escuta desatenta, mas que, quando considerado atentamente, soa profundo com temas caros à simbologia católica. 


\section{Referências:}

BASTOS, Fernando José de Menezes. Panorama das ideias estéticas no ocidente. De Platão a Kant. Brasília: Editora Universidade de Brasília, 1987. CALVANI, Carlos Eduardo. Teologia e MPB. São Paulo: Loyola, 1998.

CALVANI, Carlos Eduardo. Espiritualidades não-religiosas - desafios conceituais. Horizonte, Belo Horizonte, vol. 12, n. 356, p. 658-687, jul/set 2014.

CALVANI, Carlos Eduardo. Religião e MPB - um dueto em busca de afinação. Revista Eletrônica Correlatio v. 14, n. 28 - Dezembro de 2015, p. 29-54.

CALVANI, Carlos Eduardo. Coragem de Ser frente à angústia do destino e da morte na canção Cajuína, de Caetano Veloso. In: Bezerra, Cícero; Calvani, Carlos Eduardo e Santos, Joe Marçal. Religião: Olhares. Curitiba, CRV, 2016, p. $179-190$.

CALVANI, Carlos Eduardo. Existirmos... a que será que se destina? Choque ontológico, angústia e coragem de ser na canção Cajuína. Revista Eletrônica Correlatio, vol. 16, n. 1 - Junho de 2017, p. 99-113.

DIAS, Marcia Tosta. Os donos da voz: indústria fonográfica brasileira e mundialização da cultura. São Paulo, Boitempo, 2000.

MOURA, Roberto M. Cartola - A arte de transformar dificuldade em flor. In: Cartola. O melhor de Cartola: melodias e letras cifradas para violão, piano e teclados. São Paulo: Irmãos Vitale, 1998, p. 7-21.

PALlOTTINI, Renata. Posfácio - Do Teatro. In: HILST, Hilda. Teatro Completo. São Paulo: Globo, 2008. p. 491-517.

PEREIRA, José Carlos. Interfaces do sagrado: catolicismo popular: o imaginário religioso nas devoções marginais. Aparecida, SP: Editora Santuário, 2011.

SOUZA, André Ricardo de. Igreja in concert: padres cantores, mídia e marketing. São Paulo: Annablume: Fapesp, 2005.

TADA, Elton V. Sadao. Que samba é esse, malandro? Uma análise teológico-existencial de sambas de Cartola a partir da teologia da cultura de Paul Tillich.

Revista Eletrônica Correlatio, vol. 9, n. 18, 2010, p. 50-65.

Submetido em: 30-7-2021

Aceito em: 3-9-2021 